\title{
Article \\ Experimental Analysis of a Fuzzy Scheme against a Robust Controller for a Proton Exchange Membrane Fuel Cell System
}

\author{
Cristian Napole*(D), Mohamed Derbeli *(D) and Oscar Barambones *(D) \\ System Engineering and Automation Deparment, Faculty of Engineering of Vitoria-Gasteiz, \\ Basque Country University (UPV/EHU), 01006 Vitoria-Gasteiz, Spain \\ * Correspondence: cristianmario.napole@ehu.eus (C.N.); mderbeli001@ikasle.ehu.es (M.D.); \\ oscar.barambones@ehu.eus (O.B.)
}

Citation: Napole, C.; Derbeli, M.; Barambones, O. Experimental Analysis of a Fuzzy Scheme against a Robust Controller for a Proton Exchange Membrane Fuel Cell System. Symmetry 2022, 14, 139. https://doi.org/10.3390/ sym14010139

Academic Editor: Saeid Jafari

Received: 14 December 2021

Accepted: 4 January 2022

Published: 12 January 2022

Publisher's Note: MDPI stays neutral with regard to jurisdictional claims in published maps and institutional affiliations.

Copyright: (c) 2022 by the authors. Licensee MDPI, Basel, Switzerland. This article is an open access article distributed under the terms and conditions of the Creative Commons Attribution (CC BY) license (https:// creativecommons.org/licenses/by/ $4.0 /)$.

\begin{abstract}
Proton exchange membrane fuel cells (PEMFC) are capable of transforming chemical energy into electrical energy with zero emissions. Therefore, these devices had been a point of attention for the scientific community as to provide another solution to renewable sources of energy. Since the PEMFC is commonly driven with a power converter, a controller has to be implemented to supply a convenient voltage. This is an important task as it allows the system to be driven at an operative point, which can be related to the maximum power or an user desired spot. Along this research article, a robust controller was compared against a fuzzy logic strategy (with symmetric membership functions) where both were implemented to a commercial PEMFC through a dSPACE 1102 control board. Both proposals were analysed in an experimental test bench. Outcomes showed the advantages and disadvantages of each scheme in chattering reduction, accuracy, and convergence speed.
\end{abstract}

Keywords: fuzzy logic; fuzzy control; fuzzy set; sliding mode control; PEMFC; renewable energies

\section{Introduction}

Renewable energies are a trending topic nowadays due to the future of climate change. In this sense, current main technologies that could replace conventional sources are photovoltaic systems (conversion efficiency of $\approx 20 \%$ ), wind turbines (conversion efficiency of $\approx 25 \%$ ), and turbine generators (conversion efficiency of $\approx 30-40 \%$ ) [1,2]. Nevertheless, fuel cells are emerging technological devices that stand out over conventional renewable energy options.

These devices have captured attention since they were discovered by William Grove in 1838 when he realised a constant current can be obtained when two platinum electrodes are immersed in a sulphuric acid solution and connected to sealed tubes with oxygen and hydrogen [3]. Thenceforth, the attractiveness of fuel cells is still a trend in research as it is expected that this technology could reach its maturity near 2030 [4]. Additionally, because of the groundbreaking innovation of fuel cell electric vehicles (FCEV) and large capacity stationary fuel cells (LCSFC), the interest has been growing exponentially since 2007 [5]. This is principally due to their emissions level that could reach up to $0 \%$ (depending on the type and fuel) and a high efficiency that yields up to $60 \%[6,7]$.

Despite the types of available fuel cells, Proton exchange membrane fuel cells (PEMFC) stand out as the production emissions are the lowest and it produces high energy densities with sufficient robustness [8,9]. Still, their performance can be improved through the usage of a power converter as its able to manipulate the output voltage which the end-user may require [10]. Furthermore, as the PEMFC output voltage can vary according to the load requirement, oxygen/hydrogen feeding, and temperature, it is highly endorsed to use a control algorithm to follow an appropriate path.

Linear approaches can be a suitable first option for a shallow control of PEMFC. For instance, Kodra and Zhong [11] produced a linear quadratic regulator (LQR) for a modelled PEMFC where they controlled the feeding air and $\mathrm{H}_{2}$. Simulation outcomes 
showed suitable results in terms of settling time and overshoot reduction. A similar strategy also based on flow control has been achieved by authors of [12], where they used a linear parameter varying (LPV) model. In this case, the outcomes were gathered experimentally where capabilities of dynamic response control were achieved. Despite in real-time applications, the direct manipulation of gases for PEMFC can increase the risk of accidents because of the sensitivity of $H_{2}$ [13]. Additionally, accurate models of PEMFC are mainly non-linear due to the dependence on partial reactancts pressures and temperature [14]. On the other hand, linear strategies for converters tend to be useful in proximity of an equilibrium point along a slow response; this implies that there are numerous limitations for other operative setups [15]. For instance Belhaj et al. [10] showed in a simulated PEMFC with a power converter, suitable results can be achieved provided that an optimised PID ensures its work around an operative range. Therefore, non-linear strategies can be a reasonable approach for real PEMFC systems.

In this sense, several nonlinear techniques had been developed for PEMFC with a boost converter. Authors of [16], modelled a fuel cell where they used neural feedback linearization, which was compared with a neural and adaptive proportional-integralderivative (PID) controllers. Simulated results showed that the proposed method had better stability and reliability. Nevertheless, feedback linearization is known for its lack of robustness at parameter uncertainties [17]. A well-known robust controller that can tackle this issue is a sliding mode controller (SMC), which is also notorious for its fast convergence [18]. Bjaoui et al. [19] analysed an SMC for maximum power point tracking (MPPT) of a fuel cell with a boost converter; in this case, they obtained the results through experiments where proper outcomes were reached in terms of performance and robustness. Another example has been developed by Valderrama-Blavi et al. [20]; in this case, a boost converter arrangement for a step-up DC-AC output was designed and a SMC controller was embedded for plant order reduction. Experiments showed an increment of efficiency of around $90 \%$. However, major drawbacks of SMC are related to the chattering [21]. Even though a solution to these disadvantages is the usage of high-order SMC, this implies the employment of high order derivatives which induces an increment of noise in the feedback [22].

On the other hand, fuzzy logic control (FLC) is another strategy in which its main features reside in its simplicity of implementation and explicit configuration as it depends on expert knowledge rather than on an accurate mathematical model [23]. Usually, human knowledge is expressed through simple rules and membership functions, which can be symmetric or asymmetric [24,25]. This tool introduced by Zadeh in 1965 [26,27] has been an example of employment in decision making processes [28] and mathematical modelling [29,30]. Examples of experimental tests on a converter had been developed by Ramalu et al. [31]. In this case, they used a single ended primary-inductor converter (SEPIC) for MPPT and a FLC strategy was embedded. The gathered results showed an enhanced performance in terms of over/ undershoot reduction. Additionally, Harrag and Messalti made a study about the benefits of using FLC in a PEMFC for performance enhancement [32]. They were able to show that features like robustness improvement with reduction of response time and chattering in comparison to conventional techniques.

In this research, an FLC and a conventional SMC are contrasted in a real-time PEMFC system. The objective is the performance inspection of these structures in a constant current following when a disturbance appears. The constant value can be a variable under the requirements of an expert, which can be linked to an MPPT or a concerned efficient position. This latter effect was simulated with programmable resistance during a specific time range. Different phenomena were analysed, such as chattering, settling time, and robustness.

The arrangement of this article is as follows. Section 2 gives an overview of the used hardware like the PEMFC, boost converter, programmable load, and real-time controller board. Sections 2.2-2.4 are related to the controllers used with their details and tools used to gather suitable parameters. Section 3 shows the obtained outcomes from the experimental 
implementation of the mentioned schemes with detailed analysis. Finally, major lessons are summarised in Section 4.

\section{Materials And Methods}

\subsection{Employed Hardware}

A real-time platform was designed for the implementation of controllers and achievement of suitable performance of the system. Thus, a fuel cell Heliocentris PEMFC FC50 was used and supplied with high-purity hydrogen (99.999\% vol) from a compressed reservoir at $1 \mathrm{Mpa}$. This device is able to produce above $40 \mathrm{~W}$ with 5VCC output and a current rate of 8-10 A. Additionally, the manufacturer included a safety circuit to control the fuel supply also linked to the oxygen, inner humidity, and stack temperature.

On the other hand, the converter used in the platform is a TEP-192 boost type. This device possesses a direct control of the metal-oxide-semiconductor-field-effect transistor (MOSFET) for switching that originates from a pulse-width-modulation (PWM) signal. The maximum switching frequency is $20 \mathrm{kHz}$. This device is modelled in the electric circuit of Figure 1. The involved elements are an inductor $(\mathrm{L})$, a switching device $\left(S_{1}\right)$, a capacitor (C), a load ( $R$, as the BK Precision 8500), and a diode (D).

The device in charge of acquisition and generation of the PWM signal was a dSPACE MicroLabBox DS1202, that is a common hardware used for mechatronics investigations because of its robustness and performance. The inner configuration is based on a programmable field-programmable gate array (FPGA), with a clock that can achieve up to 2 GHz. The manufacturer included the ability to use this device under analogue, digital, or PWM signals on 100 available channels. Furthermore, dSPACE included a Real-Time Interface (RTI), a tool that helps in the C code generation and allows further concentration on the process design.

To replicate a load in the circuit, a programmable resistance BK Precision 8500 was used. This device is capable of being configured in values between 0.1 and $1000 \Omega$. In addition, the operating voltage is in the range of $0-250 \mathrm{~V}$ and the current in $0-30 \mathrm{~A}$. Further details in regards to the described hardware are enlisted in Table 1.

Table 1. Heliocentris PEMFC FC50.

\begin{tabular}{ccc}
\hline Heliocentris PEMFC FC50 & Values & Units \\
\hline Operating voltage & $2.5-9$ & VDC \\
Operating current & $0-10$ & $\mathrm{~A}$ \\
Rated output power & 40 & $\mathrm{~W}$ \\
Open-circuit voltage & 9 & $\mathrm{VDC}$ \\
\hline Boost converter TEP192 & & \\
\hline Inductance & 6 & $\mu \mathrm{H}$ \\
Input capacitor & 1500 & $\mu \mathrm{F}$ \\
Output capacitor & 3000 & $\mu \mathrm{F}$ \\
Max. input voltage & 60 & $\mathrm{~V}$ \\
Max. input current & 30 & $\mathrm{~A}$ \\
Max. output voltage & 250 & $\mathrm{~V}$ \\
Max. output current & 30 & $\mathrm{~A}$ \\
\hline
\end{tabular}

In regards to the employed software, Simulink was employed to design the proposed control architectures, whereas MATLAB was used for data and signal processing. Additionally, ControlDesk (from dSPACE) was used in real-time to verify the involved variables for performance enhancement. A descriptive resume of the described hardware and software is provided in Figure 1. 

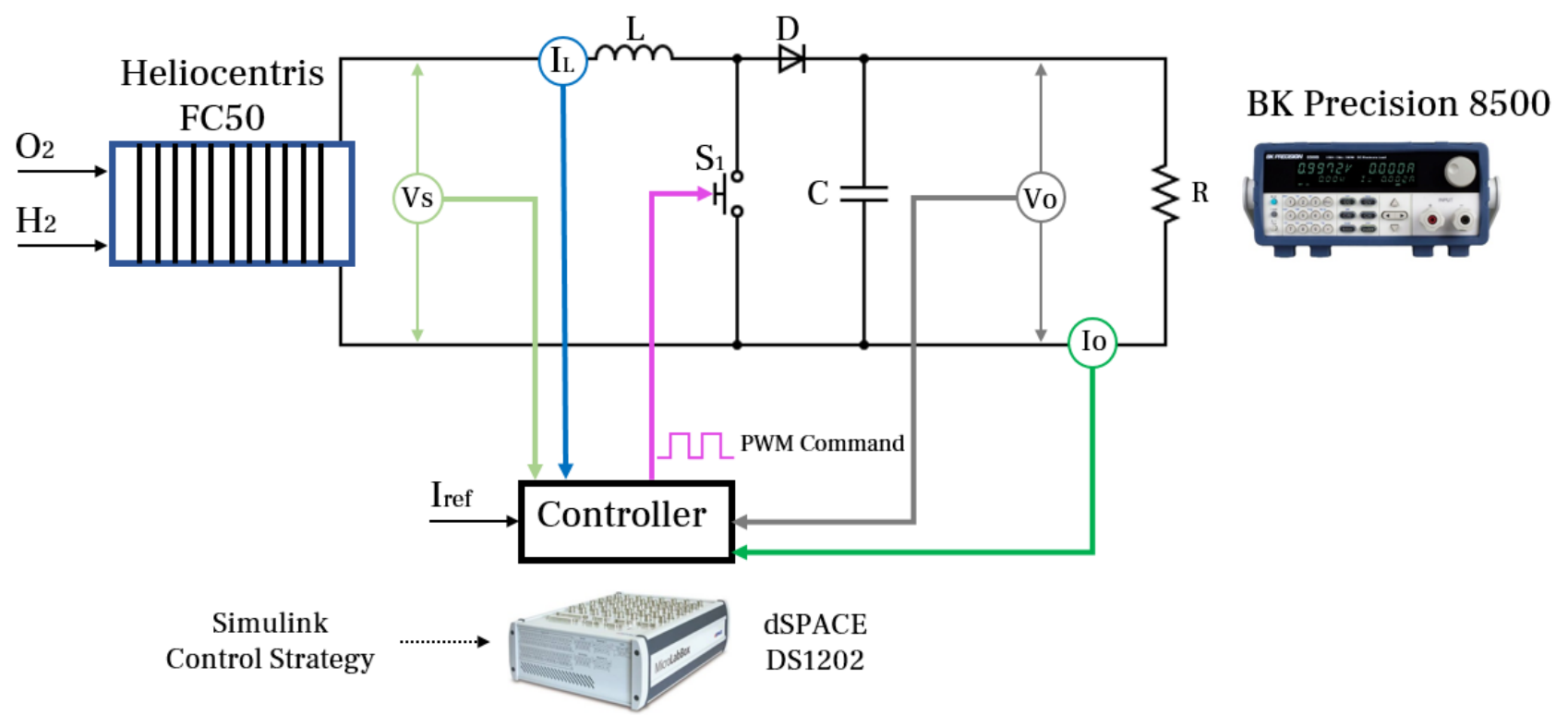

Figure 1. Hardware flow.

\subsection{Control Design}

The main objective of this work is to track a reference current $I_{r e f}$ which was carried out mainly with an FLC controller that has been contrasted with a conventional SMC. Main comparisons are aimed to test the robustness of both controllers, a well-known feature as it was previously described in background research. Hence, the error in terms of the reference current is defined as Equation (1):

$$
e=I_{r e f}-I_{L} .
$$

The output $\left(V_{o}\right)$ and stack voltages $\left(V_{S}\right)$ are related to each other by means of the duty cycle $d$. This value is driven by the PWM signal generated by the dSPACE hardware. Thus, this implies that there are two different switching arrangements that are modelled by the following state-space of Equation (2). Further details about the derivation of this system can be found in the research made by the authors in [33].

$$
\left\{\begin{array}{l}
{\left[\begin{array}{c}
\frac{d i_{L}}{d t} \\
\frac{d V_{\text {Vut }}}{d t}
\end{array}\right]=\left[\begin{array}{cc}
0 & \frac{-(1-d)}{L} \\
\frac{(1-d)}{C} & -\frac{1}{R C}
\end{array}\right] \cdot\left[\begin{array}{c}
i_{L} \\
V_{o}
\end{array}\right]+\left[\begin{array}{c}
1 \\
L \\
0
\end{array}\right] V_{S}} \\
y=\left[\begin{array}{ll}
0 & 1
\end{array}\right] \cdot\left[\begin{array}{l}
i_{L} \\
V_{o}
\end{array}\right]
\end{array}\right.
$$

Additionally, the main features of the PEMFC were useful for the following structures to be explained. In this sense, Figure 2 is the relation between stack voltage and current which was gathered experimentally. In this graph it can be seen that the fuel cell resistance $\left(R_{P E M F C}\right)$ changes when the current is reduced and vice-versa. Moreover, this mentioned resistance is related to the BK Precision $\left(R_{\mathrm{Out}}\right)$ through the duty cycle of the expression from Equation (3) [34]:

$$
R_{\text {PEMFC }}=(1-d)^{2} \cdot R_{\mathrm{Out}} .
$$




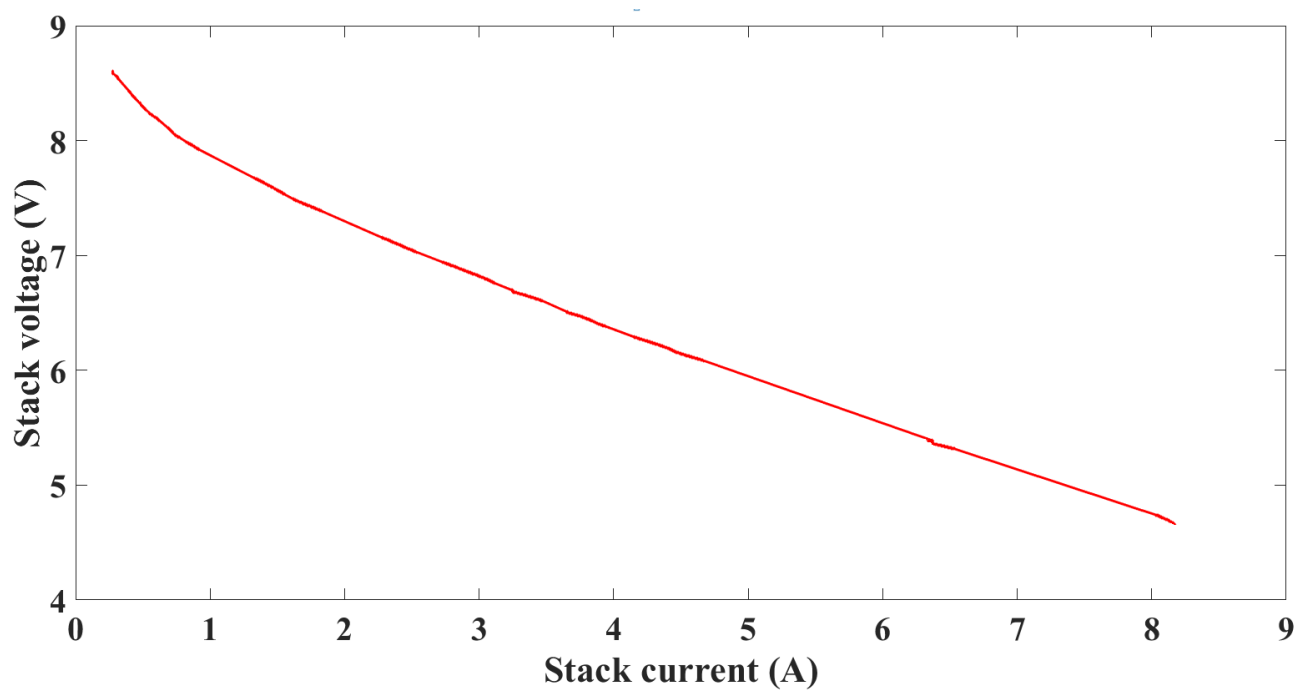

Figure 2. Characteristic dynamic curve of the fuel cell.

The proposed controllers have variables that had to be tuned. Thus, through ControlDesk it is possible to change desired gains in specific ranges that can be glided manually with the aim of achieving an objective. In regards to this goal, a real-time metric was calculated in order to figure out a suitable performance. The minimization of integral of the absolute error (IAE) was used in this case, and its mathematical expression is established in Equation (4). This definition has terms like the error $\left(e_{i}\right)$, sampling time $(\Delta t)$, and an established number of samples $(N)$ :

$$
I A E=\sum_{i=1}^{N}\left|e_{i}\right| \Delta t
$$

\subsection{Fuzzy Logic Control}

This is a robust intelligent strategy as it has rules and constraints for mathematical calculation during the process [35]. FLC works on the principle of expertise knowledge about a system so that the parameters can be tuned based on previous experience [24]. In this case, a type-1 FLC was used (defined in Figure 3); this is a fuzzy set in which the input goes though a fuzzification process. This method refers to values that are transformed into fuzzy values in the range of $[-1,1]$ through overlapped symmetric triangular membership functions which are exposed in Figure 4. Alternatives, like trapezoidal and Gaussian may require higher computational resources because of the parameters increments and analytical solutions, respectively [36].

These are also terms, such as negative big (NB), negative medium (NM), negative small (NS), zero (Z), positive small (PS), positive medium (PM), and positive big (PB) [36,37]. These previous mentioned relationships are resumed in the assymetric Table 2. Later, the evaluation of these values is conducted in the inference engine which is the point at where the expert applies and tunes linguistic rules [38]. In this case, these rules are settled conditioned variables in the form of IF-THEN structures [39,40]. The fuzzification set up had been through singleton in uniformly discretized constants within the range of $[-1,1]$.

The structure presented in Figure 3, has the described blocks of FLC and gain like $K_{e}, K_{E d}$, and $K_{o}$. These are normalisation factors, which are tuned over the real system so that the input and output ranges are in accordance to the previous specified values [41]. The suitable values of these gains were achieved through the minimisation of IAE as it was previously presented in Equation (4). 


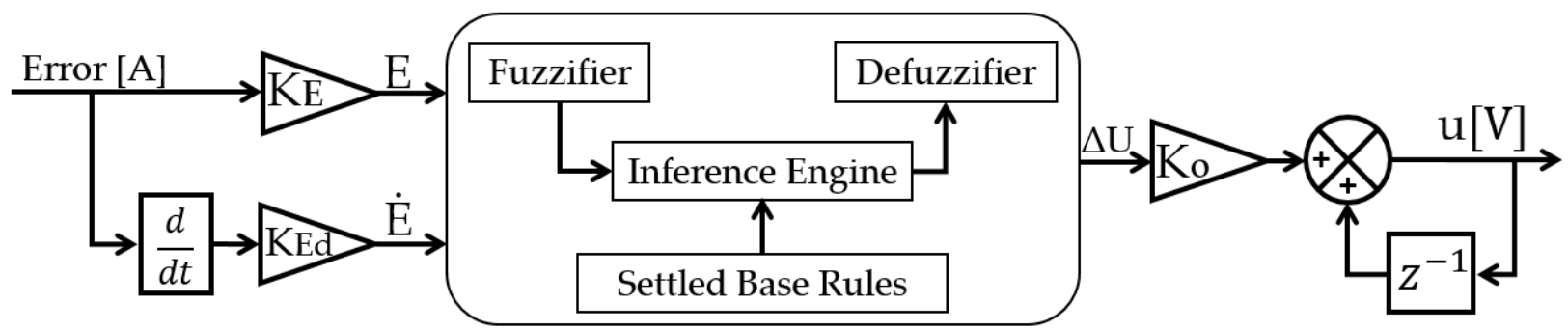

Figure 3. FLC Type-1 structure.
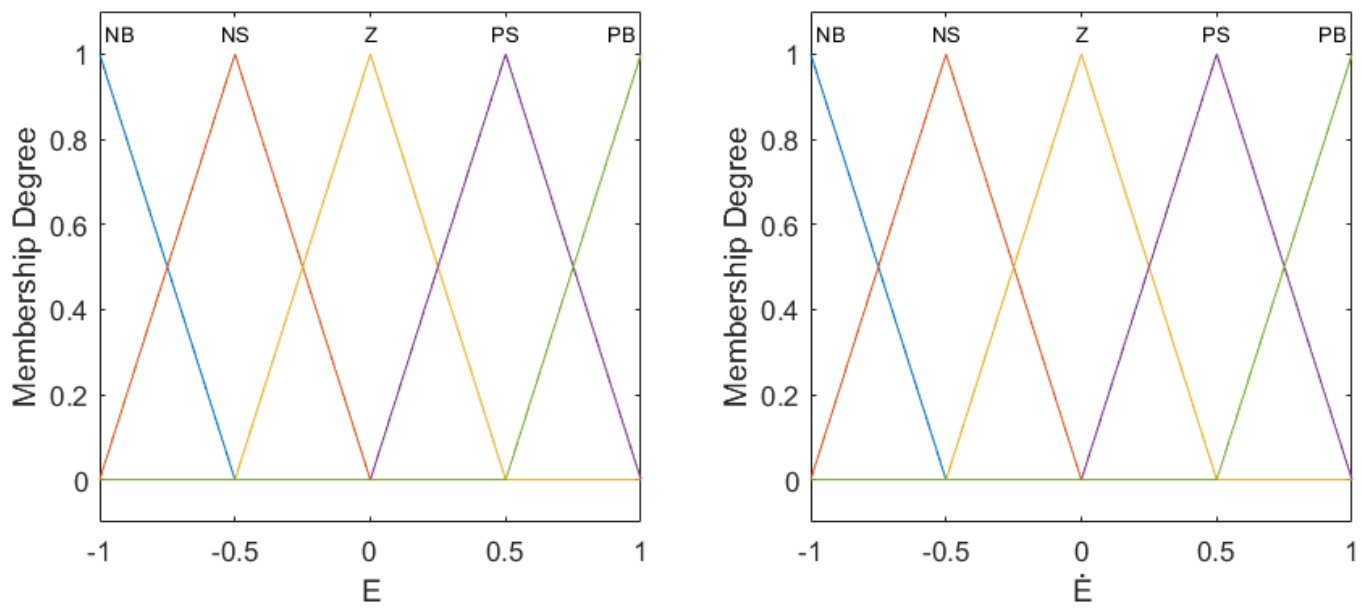

Figure 4. Membership functions.

Table 2. FLC linguistic rules.

\begin{tabular}{cccccc}
\hline $\mathbf{E} \backslash \dot{\boldsymbol{E}}$ & NB & NS & $\mathbf{Z}$ & PS & PB \\
\hline NB & NB & NM & NM & NS & Z \\
\hline NS & NM & NM & NS & Z & Z \\
\hline Z & NM & NS & Z & PS & PM \\
\hline PS & Z & Z & PS & PM & PM \\
\hline PB & Z & PS & PM & PM & PB \\
\hline
\end{tabular}

Based on Table 2, a stability proof is provided in order to show the logic of the chosen rules. Taking into account the Lyapunov stability proof establishes that a system is stable in a dynamic perspective provided that a definite positive function $V$ exists such that $V(x)>0, V(\infty)=\infty, V(0)=0 \& \dot{V}(x)<0, \forall x \neq 0$. Thus, this function is defined in Equation (5) where $E$ is a normalised error such that $E=I_{N r e f}-I_{N}$ and its derivative is $\dot{E}=-\dot{I}_{N}$. Therefore, a Lyapunov function is defined and differentiated in Equations (5) and (6):

$$
\begin{gathered}
V=\frac{1}{2} E^{2} \\
\dot{V}=E \dot{E}=-\left(I_{N r e f}-I_{N}\right) \dot{I}_{N} .
\end{gathered}
$$

Provided that Equation (6) is negative, thus, the system is asymptotically stable and the error tends to a null value. Since Table 2 is symmetric, the following reasoning is generated for one side of the table. Taking into account that the control action $U$ is related to the duty cycle, the following cases are analysed. 
- Case 1 (red cells from Table 2): $\Rightarrow U>0$. In this situation, the duty cycle increment is positive. Equation (3) shows that an increment of $d$ will decrease $R_{P E M F C}$. As $R_{P E M F C}=V_{\text {stack }} / I_{\text {stack }}$ and according to Figure 2, the resistance is reduced when the current increases. This means to move to the right of curve showed in the mentioned graph. Therefore, it can be concluded that $\dot{I}_{N}$ and $E$ will have positive values. Thus, Equation (6) will be negative.

- $\quad$ Case 2 (green cell from Table 2): $\Rightarrow U>0$. For this case, it is assumed that $\dot{E}$ is negative while $E$ is positive. Nevertheless, a positive increment of the duty cycle will cause the same action as in Case 1 where $\dot{I}_{N}$ yields to a positive, which is the same sign as $E$. Consequently, $\dot{V}<0$.

- $\quad$ Case 3 (orange cell from Table 2): $\Rightarrow U=0$. In this instance, the control action is null which implies that there is no change. Thus, since the derivative of the normalised error is positive while the error is negative, it can be concluded that $\dot{V}<0$. This reasoning can be used as well in the table diagonal since it will drive to the same conclusion.

\subsection{Sliding Mode Control}

Based on the established error of Equation (1), thus, an integral sliding surface is defined in Equation (7) where $\lambda$ is a positive value:

$$
s=e-\lambda \int e \cdot d t .
$$

A control signal generated from a SMC approach is composed by an equivalent $\left(u_{e q}\right)$ and a switching term $\left(u_{s w}\right)$, that is expressed in Equation (8) [42]. The mechanics of this controller is as follows: $u_{e q}$ aims to move the states to an equilibrium point by establishing the condition $\dot{s}=0$, which is the origin of a phase plane [43]. As it is expected that the states will move through time, then the $u_{s w}$ intention is to force the states to stay in the sliding surface $[44,45]$. The latter is defined in Equation (9) as a first-order discontinuous expression where $K$ is a parameter to be tuned and high values can increase the response time in exchange for strong oscillations that may induce hardware damage [22]:

$$
\begin{gathered}
u=u_{e q}+u_{s w} . \\
u_{s w}=-\frac{K \cdot L}{V_{o}} \cdot \operatorname{sign}(s)
\end{gathered}
$$

The derivative of the sliding surface $\dot{s}$ can be calculated using Equations (1), (2), and (7):

$$
\dot{s}=\dot{e}+\lambda e=\frac{1}{L}\left(V_{s}-V_{o}\right)+\lambda e+\frac{V_{o}}{L} u .
$$

Based on the mentioned condition $\dot{s}=0$ and the boost converter system from Equation (2), the equivalent term is expressed as the following Equation (11):

$$
u_{e q}=1-\frac{V_{s}}{V_{o}}-\frac{\lambda \cdot e \cdot L}{V_{o}} .
$$

To prove the stability of the SMC control signal which is obtained in (8), a positive definite cost function as given in Equation (12) is designed according to the Lyapunov second method criterion [46,47]:

$$
V(s)=\frac{1}{2} s^{2} .
$$


To ensure that the cost function $V$ is converging to zero in finite-time, its derivative $\dot{V}$ must be negative definite. By using Equations (8)-(11), differentiating Equation (12) with respect to time yields to:

$$
\begin{aligned}
\dot{V} & =s \cdot \dot{s} \\
& =s\left(\frac{1}{L}\left(V_{s}-V_{o}\right)+\lambda \cdot e+\frac{V_{o}}{L}\left(-\frac{k \cdot L}{V_{o}} \operatorname{sign}(s)+1-\frac{V_{s}}{V_{o}}-\frac{\lambda \cdot e \cdot L}{V_{o}}\right)\right) \\
& =-k \cdot s \cdot \operatorname{sign}(s) \\
& =-k \cdot|s| \\
& \leq 0 .
\end{aligned}
$$

Consequently, according to the Lyapunov theory, the asymptotic stability is ensured. Besides, by using Equations (12) and (13), the following demonstration can be obtained:

$$
\begin{aligned}
\frac{1}{2} \frac{d}{d t} s^{2} & =-k \cdot|s| \\
\frac{1}{2} \cdot \int_{t_{0}}^{t_{\text {reach }}} \frac{d}{d t}|s|^{2} d t & =-k \cdot \int_{t_{0}}^{t_{\text {reach }}}|s| d t \\
\frac{1}{2} \cdot \int_{t_{0}}^{t_{\text {reach }}} \frac{d}{d t}|s| d t & =-k \cdot \int_{t_{0}}^{t_{\text {reach }}} d t \\
\left|s\left(t_{\text {reach }}\right)\right|-\left|s\left(t_{0}\right)\right| & =-\left.2 \cdot k \cdot t\right|_{t_{0}} ^{t_{\text {reach }}} \\
t_{\text {reach }} & =\frac{\left|s\left(t_{0}\right)\right|}{2 \cdot k} .
\end{aligned}
$$

Therefore, the system converges to the sliding surface $s=e+\lambda \int e \cdot d t$ in the finite time $t=t_{\text {reach }}$, which implies that $\dot{s}=\dot{e}+\lambda e$ also converges to 0 . From the previous equation, the tracking error (defined by $e=c \cdot e^{-\lambda t}$ ) tends asymptotically to 0 .

\section{Experimental Results}

Both described control architectures were embedded and contrasted in the PEMFC system were the outcomes are explained as follows. Thus, the load was used to induce disturbances in the system, which occurred at $25 \mathrm{~s}$ and $45 \mathrm{~s}$. During the first action, the load step jumped from $20 \Omega$ to $50 \Omega$, which was steady until $45 \mathrm{~s}$ (where the resistance plummeted to the initial value). The controllers parameters were obtained by minimisation of the IAE. Therefore, the SMC parameters $\mathrm{K}$ and $\lambda$ were, respectively, 0.01 and 0.1 ; for the FLC, the values of $K_{E}, K_{E d}$, and $K_{o}$ were $18,0.2$, and 0.001 , respectively.

The first graph to be analysed is the acquired current, which was the variable to be followed. This is mainly because the controller objective is to keep the PEMFC current at a constant value (which is related to a desired operative point) even when external perturbations are presented. The whole experiment, which took $60 \mathrm{~s}$, is split in three subgraphs as shown in Figure $5 b-d$. The programmable resistance has uncertainty in terms of time response which can be appreciated in certain phase-delay in the results contrast. Nevertheless, the results could still be analysed in terms of robustness and response times.

In the first action of resistance increment of Figure $5 \mathrm{~b}$ at around $25 \mathrm{~s}$, the SMC induced an undershoot of $1.63 \mathrm{~A}$ whereas the FLC had a higher value of $1.79 \mathrm{~A}$. This means that the FLC has a robustness $9.81 \%$ lower than the SMC. A similar analysis can be done in the settling time in which the FLC is $60 \%$ higher in contrast to the SMC.

The second action is depicted in Figure $5 \mathrm{c}$ where the SMC still carries the trend for the fastest response. Nevertheless, the robustness is different in this case since the overshoot value of the FLC is $3.76 \mathrm{~A}$ in comparison to the SMC, which is $3.03 \mathrm{~A}$. This made a difference of $24 \%$ of better performance for the SMC.

During the constant following, the situation has a diverse demeanour in terms of absolute values. Figure 5 shows the current during the action of $50 \Omega$, which has an average 
of $4 \mathrm{~A}$ in both schemes but with different amplitudes. For instance, the SMC showed an amplitude of around $0.61 \mathrm{~A}$ whereas the FLC enhanced this value as it produced $0.25 \mathrm{~A}$, which made a difference of $60 \%$ in contrast to the SMC. This implies that the chattering is fairly reduced with the FLC approach.
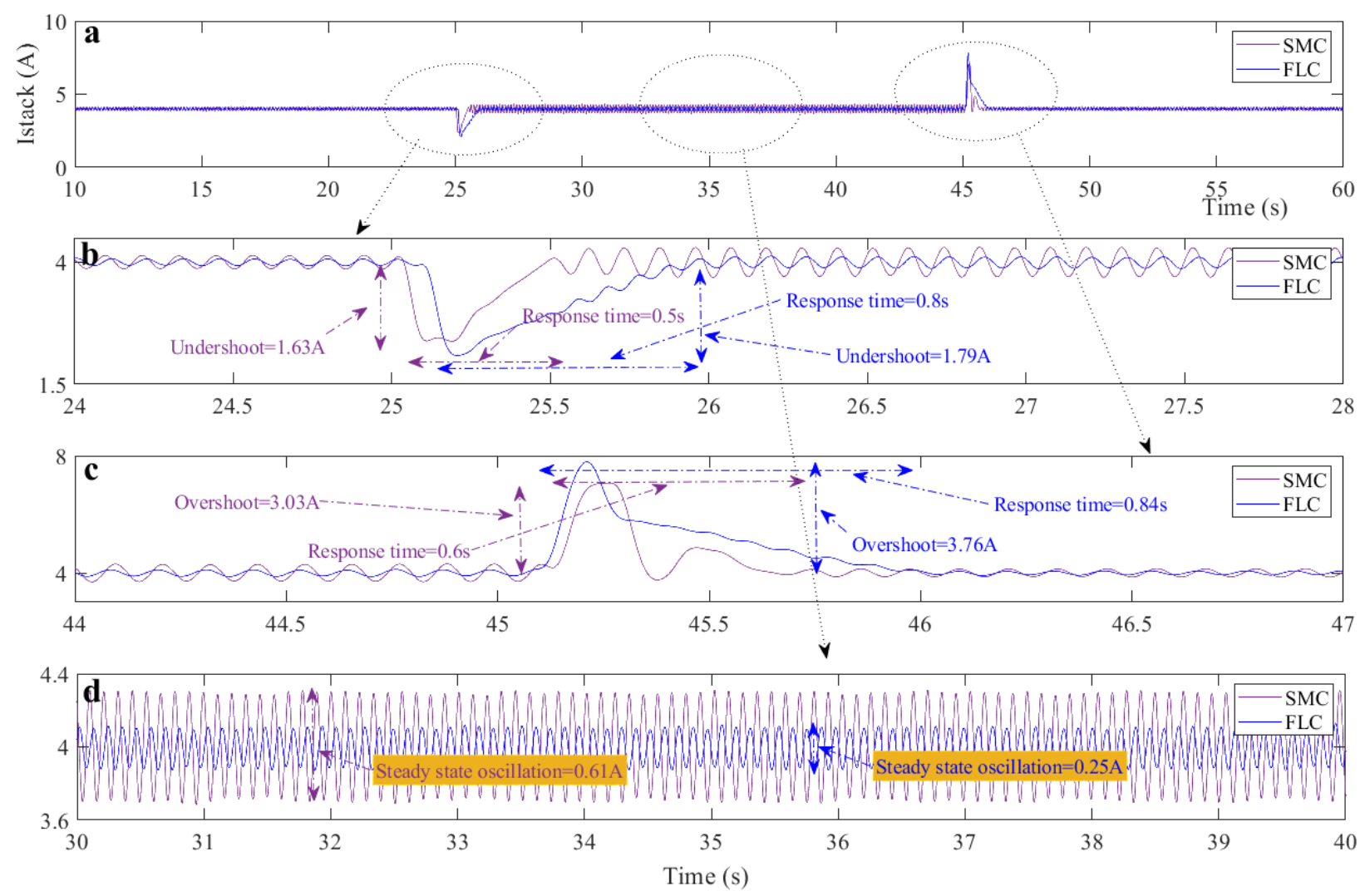

Figure 5. (a) Stack current signal; (b) influence of the first load variation; (c) influence of the second load variation; and (d) steady state.

In regards to the voltage, shown in Figure 6, the situation was similar as previously analysed in the current. The SMC showed higher chattering along the whole experiment but with slight better performance in the dynamic changes that were induced at $25 \mathrm{~s}$ and $45 \mathrm{~s}$. The overshoot value of $1.06 \mathrm{~V}$ of the FLC against the $1 \mathrm{~V}$ delivers a difference of $6 \%$, whereas the undershoot presented a difference of $2.4 \%$.

The generated power of the system was acquired as well, and is shown in Figure 7. At the first interruption of $25 \mathrm{~s}$, the SMC behaved again better than the FLC as undershoot values differed in $20 \%$. The same situation happened at $45 \mathrm{~s}$ during the resistance reduction where the overshoot was $17.5 \%$ higher with FLC in contrast to the SMC.

Finally, Figure 8 shows the boost converter duty cycle and output variables (current, voltage, and power). These real-time responses show the impact consequence of the load resistance at the previous analysed times. As previously, it can be seen that the major advantage of the FLC is its capability to reduce chattering during steady states, which allows an energy overspend. However, the SMC generates more robustness during dynamical changes.

Previous analysis results are summarized in Table 3 in terms of numbers. In this case, the overshoot, undershoot, response time and oscillation had been established as it had been the most important features to be highlighted. 

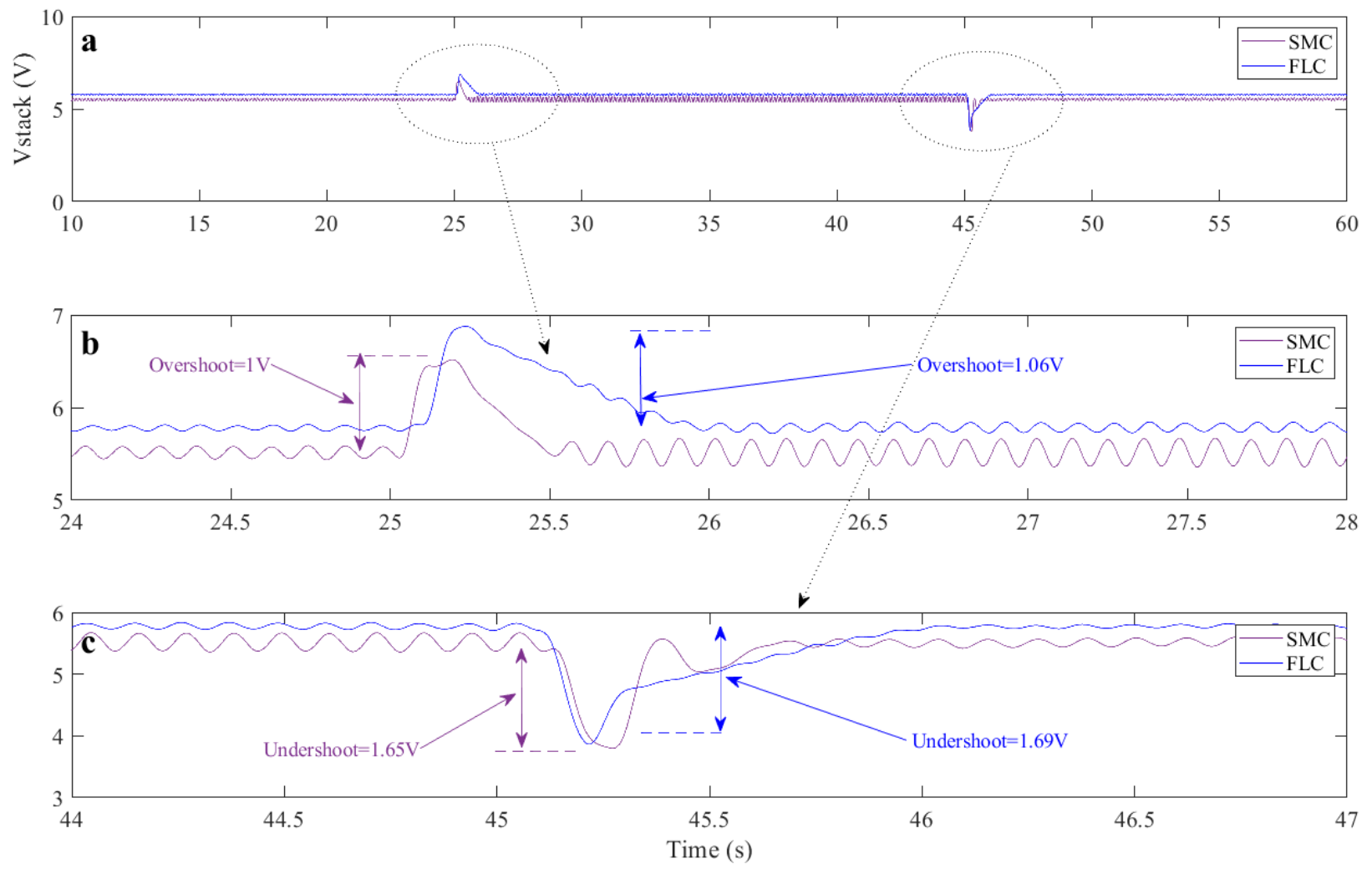

Figure 6. (a) Stack voltage signal; (b) influence of the first load variation and (c) influence of the second load variation.
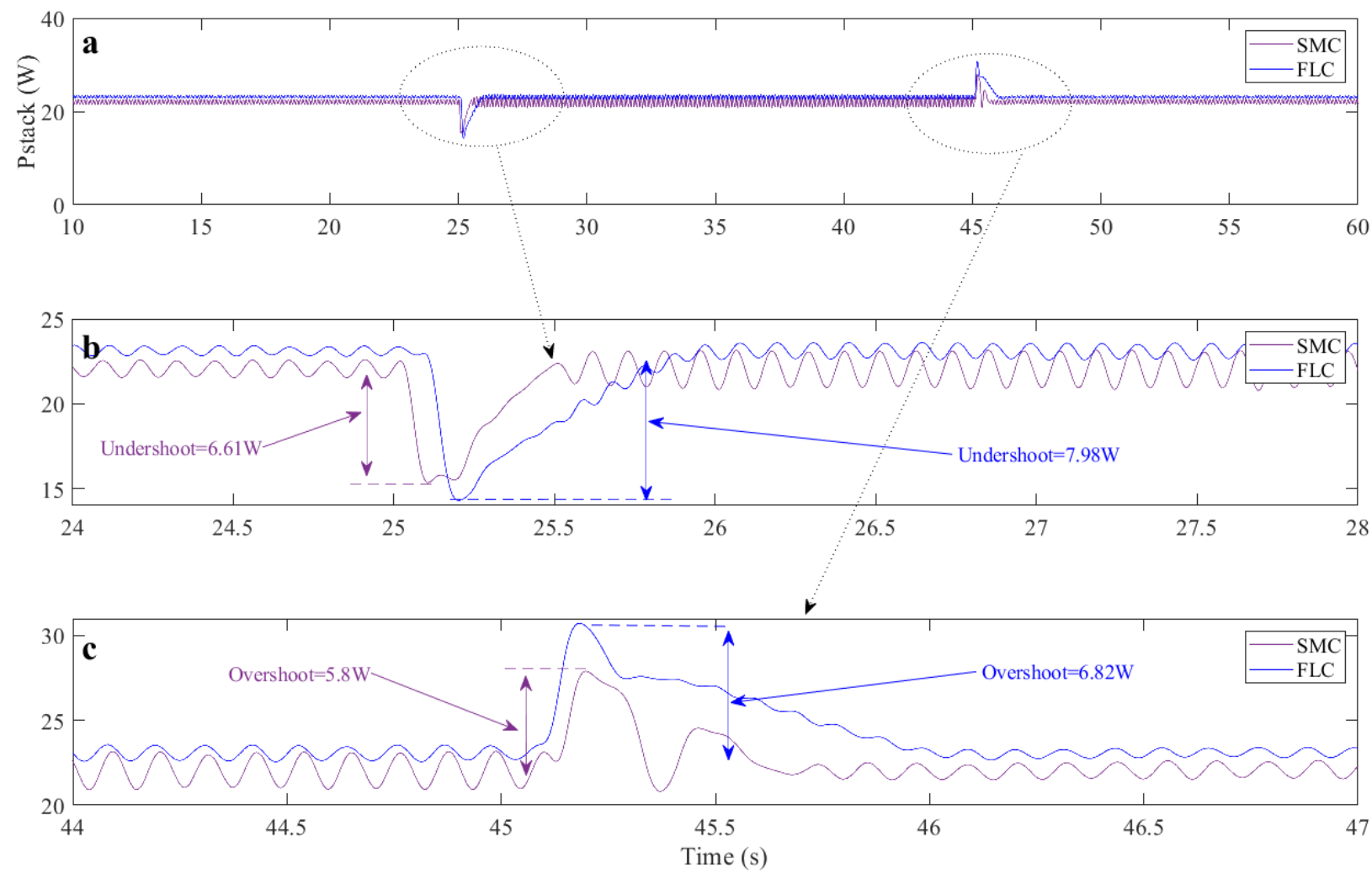

Figure 7. (a) Stack power signal; (b) influence of the first load variation and (c) influence of the second load variation. 

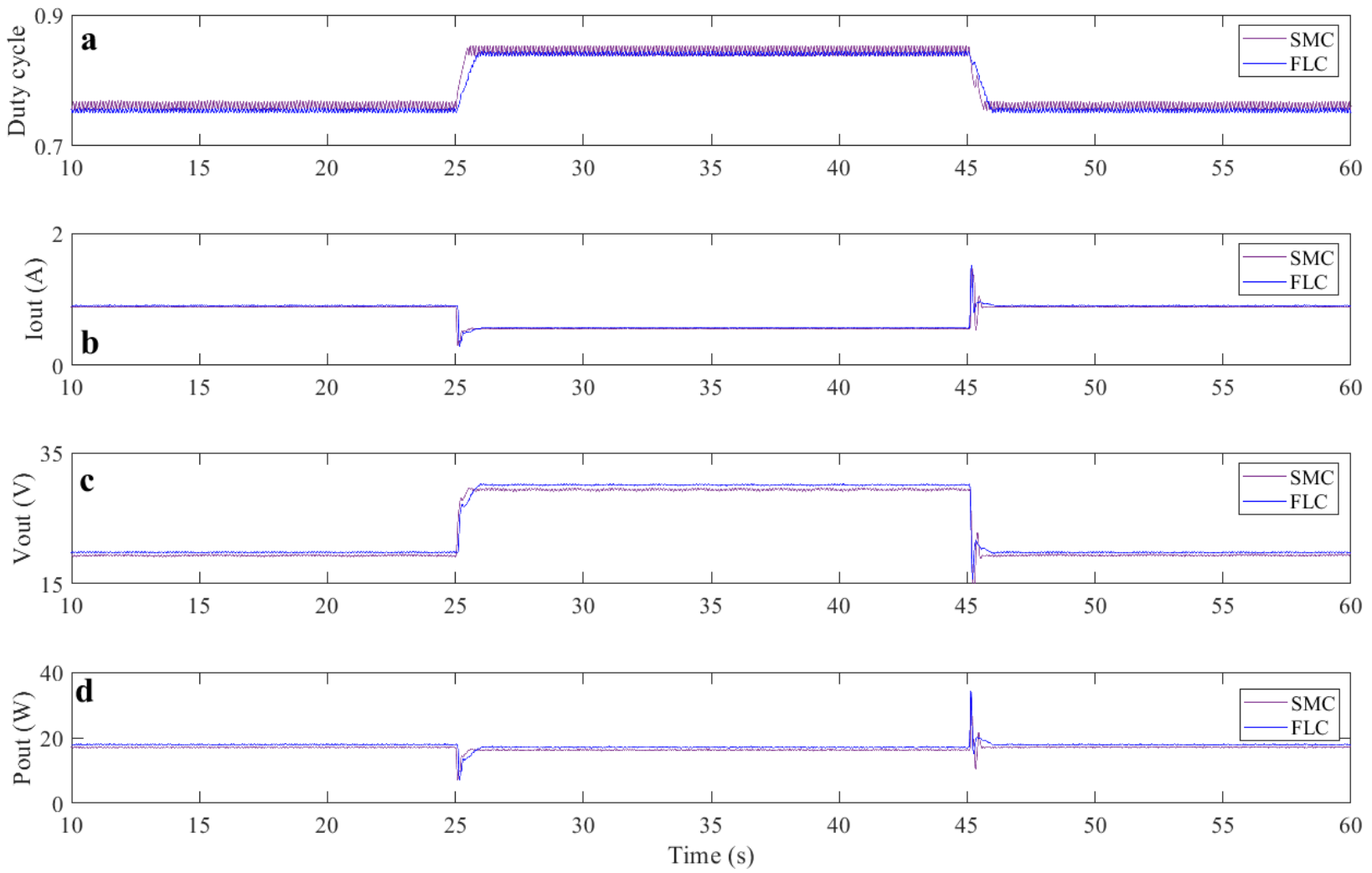

Figure 8. (a) Duty cycle signal; (b) boost converter output current; (c) boost converter output voltage; and (d) boost converter output power.

Table 3. Comparative results.

\begin{tabular}{ccccccc}
\hline & \multicolumn{2}{c}{ Current (A) } & \multicolumn{2}{c}{ Voltage (V) } & \multicolumn{2}{c}{ Power (W) } \\
& SMC & FLC & SMC & FLC & SMC & FLC \\
\hline Overshoot & 3.03 & 3.76 & 1 & 1.06 & 5.8 & 6.82 \\
Undershoot & 1.63 & 1.79 & 1.65 & 1.69 & 6.61 & 7.98 \\
Response Time & 0.5 & 0.8 & 0.5 & 0.8 & 0.5 & 0.8 \\
Oscillation & 0.61 & 0.25 & 0.33 & 0.14 & 2.2 & 0.9 \\
\hline
\end{tabular}

\section{Conclusions}

This research depicted a comparative analysis of two control algorithms aimed to enhance the performance of a PEMFC during a constant reference following disturbances. Additionally, the usage of a real system constraints theoretical ranges of power and duty cycle.

The objective was to maintain a constant current following that can be associated to a user-desired operative point or an MPPT. This target usually has inconveniences, such as external disturbances as analysed. SMC was chosen for its capabilities in robustness and fast response. FLC is known for its expertise involvement so that the tuning can be made from a personal perspective.

A programmable load was adopted to simulate an peripheral charge which affects the circuit. In addition, commercial hardware was used to generate a real environment where the proposed control structures were embedded with a dSPACE controller board in real-time. The latter mentioned device was also used for acquisition of signals and further processing with MATLAB.

Both control architectures were implemented where several interesting points were highlighted. For instance, it was shown that the SMC provided suitable capabilities in terms of robustness. In this sense, SMC had better robustness during dynamical changes, 
such as sudden load variations. Additionally, another suitable observed feature was the fast response. These aspects were noticed in variables such as current, voltage, and power.

Despite the dynamical changes, the SMC was superior in terms of performance, the FLC promoted an attractive efficacy during the constant following. In this case, for SMC, it was already known that its main disadvantage is related to the chattering generation, which was observed in the outcomes. Thus, FLC reduced this feature, not only providing better accuracy but also an energy reduction which could enhance system efficiency.

To conclude this research, future perspective lines are based on different branches of the analysed control structures. For instance, a study of a FLC Type-2 with different inference algorithms can be an interesting comparison. Additionally, the FLC used in this case had the aim to track a constant reference, thus it would be intriguing to implement the same algorithm for MPPT where the reference is a variable.

Author Contributions: Conceptualisation, O.B., M.D. and C.N.; methodology, M.D. and C.N.; software, C.N.; validation, M.D.; formal analysis, O.B., M.D. and C.N.; investigation, O.B. and C.N.; resources, O.B.; writing - original draft preparation, C.N.; writing-review and editing, O.B., C.N. and M.D.; supervision, O.B.; project administration, O.B. All authors have read and agreed to the published version of the manuscript.

Funding: This research was funded by the Basque Government through project EKOHEGAZ (ELKARTEK KK-2021/00092), by the Diputación Foral de Álava (DFA), through project CONAVANTER, and by the UPV/EHU, through project GIU20/063.

Institutional Review Board Statement: Not applicable.

Informed Consent Statement: Not applicable.

Acknowledgments: The authors wish to express their gratitude to the Basque Government, through project EKOHEGAZ (ELKARTEK KK-2021/00092), to the Diputación Foral de Álava (DFA), through project CONAVANTER, and to the UPV/EHU, through project GIU20/063, for supporting this work.

Conflicts of Interest: The authors declare no conflict of interest.

\begin{tabular}{|c|c|}
\hline \multicolumn{2}{|c|}{ Abbreviations } \\
\hline \multicolumn{2}{|c|}{ The following abbreviations are used in this manuscript: } \\
\hline PEMFC & Proton exchange membrane fuel cells \\
\hline FCEV & Fuel cell electric vehicles \\
\hline LCSFC & Large capacity stationary fuel cells \\
\hline LQR & Linear quadratic regulator \\
\hline LPV & Linear parameter varying \\
\hline PID & Proportional-integral-derivative \\
\hline SMC & Sliding mode control \\
\hline MPPT & Maximum power point tracking \\
\hline FLC & Fuzzy logic control \\
\hline SEPIC & Single ended primary-inductor converter \\
\hline MOSFET & Metal-oxide-semiconductor-field-effect transistor \\
\hline PWM & Pulse-width-modulation \\
\hline FPGA & Field-programmable gate array \\
\hline RTI & Real-time interface \\
\hline
\end{tabular}

\section{References}

1. Hasan, A.; McCormack, S.J.; Huang, M.J.; Norton, B. Energy and Cost Saving of a Photovoltaic-Phase Change Materials (PV-PCM) System through Temperature Regulation and Performance Enhancement of Photovoltaics. Energies 2014, 7, 1318-1331. [CrossRef]

2. Mahapatra, M.K.; Singh, P. Chapter 24-Fuel Cells: Energy Conversion Technology. In Future Energy, 2nd ed.; Letcher, T.M., Ed.; Elsevier: Boston, MA, USA, 2014; pp. 511-547. [CrossRef]

3. Andújar, J.; Segura, F. Fuel cells: History and updating. A walk along two centuries. Renew. Sustain. Energy Rev. 2009, 13, 2309-2322. [CrossRef]

4. Ho, J.; Saw, E.C.; Lu, L.; Liu, J. Technological barriers and research trends in fuel cell technologies: A citation network analysis. Technol. Forecast. Soc. Chang. 2014, 82, 66-79. [CrossRef] 
5. Weidner, E.; Cebolla, R.O.; Davies, J. Global deployment of large capacity stationary fuel cells. In JRC Technical Reports; Joint Research Centre: Ispra, Italy, 2019. [CrossRef]

6. Yonoff, R.E.; Ochoa, G.V.; Cardenas-Escorcia, Y.; Silva-Ortega, J.I.; Meriño-Stand, L. Research trends in proton exchange membrane fuel cells during 2008-2018: A bibliometric analysis. Heliyon 2019, 5, e01724. [CrossRef] [PubMed]

7. Louzazni, M.; Al-Dahidi, S.; Mussetta, M. Fuel Cell Characteristic Curve Approximation Using the Bézier Curve Technique. Sustainability 2020, 12, 8127. [CrossRef]

8. Mayyas, A.; Mann, M. Emerging Manufacturing Technologies for Fuel Cells and Electrolyzers. Procedia Manuf. 2019, 33, 508-515. [CrossRef]

9. Abdelkareem, M.A.; Elsaid, K.; Wilberforce, T.; Kamil, M.; Sayed, E.T.; Olabi, A. Environmental aspects of fuel cells: A review. Sci. Total Environ. 2021, 752, 141803. [CrossRef] [PubMed]

10. Belhaj, F.Z.; El Fadil, H.; Idrissi, Z.E.; Koundi, M.; Gaouzi, K. Modeling, Analysis and Experimental Validation of the Fuel Cell Association with DC-DC Power Converters with Robust and Anti-Windup PID Controller Design. Electronics 2020, 9, 1889. [CrossRef]

11. Kodra, K.; Zhong, N. Singularly Perturbed Modeling and LQR Controller Design for a Fuel Cell System. Energies 2020, $13,2735$. [CrossRef]

12. Chen, F.X.; Jiao, J.R.; Liu, S.G.; Yu, Y.; Xu, S.C. Control-oriented LPV Modeling for the Air Supply System of Proton Exchange Membrane Fuel Cells. Fuel Cells 2018, 18, 433-440. [CrossRef]

13. Rosli, R.; Majlan, E.H.; Wan Daud, W.; Hamid, S. Hydrogen rate manipulation of proton exchange membrane fuel cell (PEMFC) stack using feedback control system. In Proceedings of the 2012 IEEE International Conference on Power and Energy (PECon), Kota Kinabalu, Malaysia, 2-5 December 2012; pp. 553-557. [CrossRef]

14. Cruz Rojas, A.; Lopez Lopez, G.; Gomez-Aguilar, J.F.; Alvarado, V.M.; Sandoval Torres, C.L. Control of the Air Supply Subsystem in a PEMFC with Balance of Plant Simulation. Sustainability 2017, 9, 73. [CrossRef]

15. Wang, M.; Tang, F.; Wu, X.; Niu, J.; Zhang, Y.; Wang, J. A Nonlinear Control Strategy for DC-DC Converter with Unknown Constant Power Load Using Damping and Interconnection Injecting. Energies 2021, 14, 3031. [CrossRef]

16. Awais, M.; Khan, L.; Ahmad, S.; Jamil, M. Feedback-Linearization-Based Fuel-Cell Adaptive-Control Paradigm in a Microgrid Using a Wavelet-Entrenched NeuroFuzzy Framework. Energies 2021, 14, 1850. [CrossRef]

17. Chen, Y.T.; Yu, C.S.; Chen, P.N. Feedback Linearization Based Robust Control for Linear Permanent Magnet Synchronous Motors. Energies 2020, 13, 5242. [CrossRef]

18. Li, T.; Liu, X. Model-Free Non-Cascade Integral Sliding Mode Control of Permanent Magnet Synchronous Motor Drive with a Fast Reaching Law. Symmetry 2021, 13, 1680. [CrossRef]

19. Bjaoui, M.; Khiari, B.; Benadli, R.; Memni, M.; Sellami, A. Practical Implementation of the Backstepping Sliding Mode Controller MPPT for a PV-Storage Application. Energies 2019, 12, 3539. [CrossRef]

20. Valderrama-Blavi, H.; Rodríguez-Ramos, E.; Olalla, C.; Genaro-Muñoz, X. Sliding-Mode Approaches to Control a Microinverter Based on a Quadratic Boost Converter. Energies 2019, 12, 3697. [CrossRef]

21. Wang, B.; Jahanshahi, H.; Volos, C.; Bekiros, S.; Yusuf, A.; Agarwal, P.; Aly, A.A. Control of a Symmetric Chaotic Supply Chain System Using a New Fixed-Time Super-Twisting Sliding Mode Technique Subject to Control Input Limitations. Symmetry 2021, 13, 1257. [CrossRef]

22. Napole, C.; Derbeli, M.; Barambones, O. A global integral terminal sliding mode control based on a novel reaching law for a proton exchange membrane fuel cell system. Appl. Energy 2021, 301, 117473. [CrossRef]

23. Muthugala, M.A.V.J.; Vega-Heredia, M.; Mohan, R.E.; Vishaal, S.R. Design and Control of a Wall Cleaning Robot with AdhesionAwareness. Symmetry 2020, 12, 122. [CrossRef]

24. Khairuddin, S.H.; Hasan, M.H.; Hashmani, M.A.; Azam, M.H. Generating Clustering-Based Interval Fuzzy Type-2 Triangular and Trapezoidal Membership Functions: A Structured Literature Review. Symmetry 2021, 13, 239. [CrossRef]

25. Viswanathan, K.; Oruganti, R.; Srinivasan, D. Non-linear function controller: A simple alternative to fuzzy logic controller for a power electronic converter. In Proceedings of the 30th Annual Conference of IEEE Industrial Electronics Society, 2004, IECON 2004, Busan, Korea, 2-6 November 2004; Volume 3, pp. 2655-2660. [CrossRef]

26. Khan, W.A.; Ali, B.; Taouti, A. Bipolar Picture Fuzzy Graphs with Application. Symmetry 2021, 13, 1427. [CrossRef]

27. Parimala, M.; Jafari, S.; Riaz, M.; Aslam, M. Applying the Dijkstra Algorithm to Solve a Linear Diophantine Fuzzy Environment. Symmetry 2021, 13, 1616. [CrossRef]

28. Liu, D.; Huang, A.; Liu, Y.; Liu, Z. An Extension TOPSIS Method Based on the Decision Maker's Risk Attitude and the Adjusted Probabilistic Fuzzy Set. Symmetry 2021, 13, 891. [CrossRef]

29. Georgieva, A.; Pavlova, A. Fuzzy Sawi Decomposition Method for Solving Nonlinear Partial Fuzzy Differential Equations. Symmetry 2021, 13, 1580. [CrossRef]

30. Pedraza, T.; Ramos-Canós, J.; Rodríguez-López, J. Aggregation of Weak Fuzzy Norms. Symmetry 2021, 13, 1908. [CrossRef]

31. Ramalu, T.; Mohd Radzi, M.A.; Mohd Zainuri, M.A.A.; Abdul Wahab, N.I.; Abdul Rahman, R.Z. A Photovoltaic-Based SEPIC Converter with Dual-Fuzzy Maximum Power Point Tracking for Optimal Buck and Boost Operations. Energies 2016, 9, 604. [CrossRef]

32. Harrag, A.; Messalti, S. How fuzzy logic can improve PEM fuel cell MPPT performances? Int. J. Hydrog. Energy 2018, 43, 537-550. [CrossRef] 
33. Derbeli, M.; Barambones, O.; Silaa, M.Y.; Napole, C. Real-Time Implementation of a New MPPT Control Method for a DC-DC Boost Converter Used in a PEM Fuel Cell Power System. Actuators 2020, 9, 105. [CrossRef]

34. Farhat, M.; Barambones, O.; Sbita, L. Efficiency optimization of a DSP-based standalone PV system using a stable single input fuzzy logic controller. Renew. Sustain. Energy Rev. 2015, 49, 907-920. [CrossRef]

35. Urrea, C.; Jara, D. Design, Analysis, and Comparison of Control Strategies for an Industrial Robotic Arm Driven by a Multi-Level Inverter. Symmetry 2021, 13, 86. [CrossRef]

36. Azam, M.H.; Hasan, M.H.; Hassan, S.; Abdulkadir, S.J. A Novel Approach to Generate Type-1 Fuzzy Triangular and Trapezoidal Membership Functions to Improve the Classification Accuracy. Symmetry 2021, 13, 1932. [CrossRef]

37. Napole, C.; Derbeli, M.; Barambones, O. Fuzzy Logic Approach for Maximum Power Point Tracking Implemented in a Real Time Photovoltaic System. Appl. Sci. 2021, 11, 5927. [CrossRef]

38. Sałabun, W.; Shekhovtsov, A.; Pamučar, D.; Wątróbski, J.; Kizielewicz, B.; Więckowski, J.; Bozanić, D.; Urbaniak, K.; Nyczaj, B. A Fuzzy Inference System for Players Evaluation in Multi-Player Sports: The Football Study Case. Symmetry 2020, 12, 2029. [CrossRef]

39. Sangeetha, V.; Krishankumar, R.; Ravichandran, K.S.; Cavallaro, F.; Kar, S.; Pamucar, D.; Mardani, A. A Fuzzy Gain-Based Dynamic Ant Colony Optimization for Path Planning in Dynamic Environments. Symmetry 2021, 13, 280. [CrossRef]

40. Wen, X.; Zhang, X.; Lei, T. Intuitionistic Fuzzy (IF) Overlap Functions and IF-Rough Sets with Applications. Symmetry 2021, 13, 1494. [CrossRef]

41. Napole, C.; Barambones, O.; Calvo, I.; Derbeli, M.; Silaa, M.Y.; Velasco, J. Advances in Tracking Control for Piezoelectric Actuators Using Fuzzy Logic and Hammerstein-Wiener Compensation. Mathematics 2020, 8, 2071. [CrossRef]

42. Hong, Q.; Shi, Y.; Chen, Z. Adaptive Sliding Mode Control Based on Disturbance Observer for Placement Pressure Control System. Symmetry 2020, 12, 1057. [CrossRef]

43. Zenteno-Torres, J.; Cieslak, J.; Dávila, J.; Henry, D. Sliding Mode Control with Application to Fault-Tolerant Control: Assessment and Open Problems. Automation 2021, 2, 1-30. [CrossRef]

44. Lin, C.H.; Hsiao, F.Y. Proportional-Integral Sliding Mode Control with an Application in the Balance Control of a Two-Wheel Vehicle System. Appl. Sci. 2020, 10, 5087. [CrossRef]

45. Munteanu, L.; Dumitriu, D.; Brisan, C.; Bara, M.; Chiroiu, V.; Nedelcu, N.; Rugina, C. Sliding Mode Control and Geometrization Conjecture in Seismic Response. Symmetry 2021, 13, 353. [CrossRef]

46. Kalman, R.E.; Bertram, J.E. Control system analysis and design via the "second method" of Lyapunov: I-Continuous-time systems. J. Basic Eng. 1960, 82, 371-393. [CrossRef]

47. LaSalle, J.; Lefschetz, S. Stability by Lyapunov's Second Method with Applications; Academic Press: New York, NY, USA, 1961; Volume 5, pp. 371-393. 